\title{
An Obligately Autotrophic Mutant of Chlamydomonas dysosmos: a Biochemical Elucidation
}

\author{
By A. H. NEILSON \\ Botaniska Institutionen, Lilla Frescati, S-ı04 05, Stockholm, 50, Sweden \\ AND O. HOLM-HANSEN AND R. A. LEWIN \\ Scripps Institution of Oceanography, La Jolla, California, 92037, U.S.A.
}

(Accepted for publication 14 January 1972)

\begin{abstract}
SUMMAR Y
Chlamydomonas dysosmos is a unicellular, flagellate, green alga. Wild-type cells, normally photosynthetic, are also facultatively heterotrophic, being capable of growth in darkness with acetate as sole source of carbon. A mutant induced by ultraviolet light lacked the ability to grow heterotrophically and formed negligible amounts of isocitrate lyase after $70 \mathrm{~h}$ in darkness with acetate, the specific activity being less than $3 \%$ of that found in the wild-type. Uptake of acetate after $9 \mathrm{~h}$ was only $0.3 \%$ of that by the wild-type. ATP increased slightly during the first $\mathrm{I} 0 \mathrm{~h}$ after addition of acetate and thereafter decreased, in contrast to wild-type cells, in which ATP synthesis continued under similar conditions. Thus $C$. dysosmos could normally incorporate acetate for heterotrophic growth via the glyoxylate cycle but, in the mutant, this cycle was impaired, the alga being unable to synthesize isocitrate lyase and being thereby rendered obligately autotrophic.
\end{abstract}

\section{INTRODUCTION}

Problems of autotrophy and heterotrophy should be considered in the broad context of comparative biochemistry, since common principles underlie the metabolisms of both prokaryotes and eukaryotes. There are relatively few examples of facultative heterotrophy among photoautotrophic and chemoautotrophic prokaryotic micro-organisms. No single explanation suffices for all of the known facts, but it seems that obligately autotrophic prokaryotes are generally unable to synthesize $\alpha$-ketoglutarate dehydrogenase, and thus lack a functional tricarboxylic acid cycle (references in Peeters, Liu \& Aleem, 1970). Nevertheless, several strains of blue-green algae are able to incorporate acetate into cell material in the light and in the presence of $\mathrm{CO}_{2}$ (Hoare, Hoare \& Moore, 1967). Similarly, some obligately chemoautotrophic thiobacilli take up acetate when $\mathrm{CO}_{2}$ is present and energy is available from thiosulphate oxidation (Kelly, 1967; Smith, London \& Stanier, 1967). In none of these examples, however, is heterotrophic growth possible at the expense of acetate.

While some eukaryotic green algae are obligate photoautotrophs, others are able to grow in the dark at the expense of acetate. In an attempt to elucidate the nature of facultative heterotrophy in such algae, Lewin (1954) studied Chlamydomonas dysosmos and an obligately autotrophic mutant derived from it by ultraviolet irradiation. Both strains had comparable growth rates in light, but the mutant was unable to grow on acetate in the dark. Respirometric studies showed that both strains were able to oxidize exogenous acetate, but that whereas the mutant oxidized it completely to $\mathrm{CO}_{2}$, the wild-type oxidized only part, the remainder then being available for synthesis of cell material. 
The role and functioning of the anaplerotic glyoxylate cycle in micro-organisms growing on acetate has been elucidated, largely through the work of Kornberg and his co-workers (Kornberg, I966). This cycle serves to replenish succinate and malate which are removed from the TCA cycle for biosynthetic processes. Synthesis of these acid anions depends on two enzymes, isocitrate lyase and malate synthetase, which are normally induced by the presence of acetate in the growth medium.

Associated with the assay of isocitrate lyase are certain technical problems which do not always seem to have been noted (cf. McFadden, I969). Haigh \& Beevers (1964) described a modification of the assay which overcomes interference by other keto-acids, specifically $\alpha$-ketoglutarate. They applied the method to assay isocitrate lyase in a number of algae, including the two strains of Chlamydomonas dysosmos which Lewin studied, and found that neither strain synthesized the enzyme under photoautotrophic conditions, and that only the wild-type did so in the presence of acetate in the dark. In both, acetate induced enzyme synthesis in the light, which is perhaps surprising as light suppresses such enzyme synthesis in Chlorella vulgaris (Syrett, Merrett \& Bocks, 1963; Syrett, 1966). It implies that the mutant strain of Chlamydomonas dysosmos retains the potential for isocitrate lyase synthesis, and differs from the wild-type in a regulatory mechanism whereby this is repressed when cells are transferred to darkness. The present study was undertaken because these strains provide favourable material for investigations into the nature of obligate autotrophy.

\section{METHODS}

Organisms and growth. The organisms used were the wild-type Chlamydomonas dysosmos (Cambridge Culture Collection II/36a), and the mutant D2075 derived from it. Both are maintained as stock cultures in this laboratory on agar slopes of the medium of Lewin (I95I).

Organisms were grown in Erlenmeyer flasks $(500 \mathrm{ml})$ containing $200 \mathrm{ml}$ of either the medium of Hughes, Gorham \& Zehnder (1958) with the concentration of sodium nitrate tripled (medium $\mathrm{G}$ ), or a buffered medium containing ( $\mathrm{g} / \mathrm{l}$ glass-distilled water): tris, 0.6 ; $\mathrm{NaNO}_{3}, \mathrm{I} \cdot 0 ; \mathrm{K}_{2} \mathrm{HPO}_{4} \cdot 3 \mathrm{H}_{2} \mathrm{O}, 0 \cdot \mathrm{I} ; \mathrm{MgSO}_{4} \cdot 7 \mathrm{H}_{2} \mathrm{O}, 0 \cdot \mathrm{I} 25 ; \mathrm{CaCl}_{2} .2 \mathrm{H}_{2} \mathrm{O}, 0.033 ;$ ferric potassium ethylenediaminetetra-acetate solution (Jacobson, I95I), 0.3 ml/1; and trace element solution (Lewin \& Lewin, I967), I.0 ml/1 (medium T8). The medium was adjusted to $\mathrm{pH} 8$ before autoclaving. Cultures were kept at $2 \mathrm{I}{ }^{\circ} \mathrm{C}$, agitated with magnetic stirrers; they were not gassed. Those in the light were illuminated with cool-white fluorescent lamps giving a light intensity of about $2000 \mathrm{~lx}$ at the surface of the flasks. Cultures to be kept in the dark were enclosed in wooden boxes, sealed with black tape at the seams and fitted with overlapping but loose-fitting lids which permitted free air exchange. All experiments were carried out in air.

Solutions of sodium acetate dihydrate (10 \% or $20 \%$ ) were sterilized by autoclaving and added aseptically to give final concentrations of $0.1 \%$ or $0.2 \% . N-(3,4$, dichlorophenyl)$N^{\prime}, N^{\prime}$-dimethyl urea (DCMU) was prepared as a $2.5 \times 10^{-3} \mathrm{M}$ solution in $50 \%$ ethanol, sterilized by filtration and added to media to give a final concentration of $1 \mathrm{IO}^{-5} \mathrm{M}$.

Induction experiments. Algae were grown photoautotrophically without acetate, harvested aseptically by centrifugation in the late exponential phase, and resuspended in $500 \mathrm{ml}$ of sterile medium. Potential synthesis of glyoxylate cycle enzymes was induced by addition of sterile sodium acetate solution to give a concentration of $0.2 \%$, and the algal suspension was stirred either in darkness, or in the light, with or without the addition of DCMU.

Preparation of extracts and assay of isocitrate lyase EC. 4.I.3.I. For enzyme assays, culture samples (40 to $70 \mathrm{ml}$ ) were removed aseptically, and the algae collected by centri- 
fugation for $10 \mathrm{~min}$ at $2{ }^{\circ} \mathrm{C}$, washed with cold buffer $(\mathrm{pH} \mathrm{7.5)}$ containing tris (O.I M) and $\mathrm{MgCl}_{2}(3 \mathrm{~mm})$, and recentrifuged at $2{ }^{\circ} \mathrm{C}$. They were either used immediately or stored at $-20^{\circ} \mathrm{C}$. Cells were resuspended in $2.5 \mathrm{ml}$ buffer to which $0.1 \mathrm{ml}$ dithiothreitol $(30 \mathrm{mM})$ in buffer was added, and were disrupted at $2{ }^{\circ} \mathrm{C}$ for $2 \mathrm{~min}$ in a Sonifier Cell Disruptor Model I $40 \mathrm{D}$ (Heat Systems-Ultrasonics). The sonifier chamber was kept in an ice-salt bath and rotated continuously to prevent overheating. The suspension was centrifuged first at $1000 \mathrm{~g}$ for $5 \mathrm{~min}$, and then at I $1000 \mathrm{~g}$ for $25 \mathrm{~min}$; this gave a clear, usually greenish, supernatant which was used for enzyme assay. The pellet had almost no isocitrate lyase activity.

The assay for isocitrate lyase was carried out by the method of McFadden (1969). Since we were interested in relative rather than absolute amounts, the values for specific activity were not corrected for the presence of $\alpha$-ketoglutarate by the method of Haigh $\&$ Beevers (1964). The clear supernatant $(0.3 \mathrm{ml})$ was usually used for each assay, which was carried out at $30^{\circ} \mathrm{C}$. The reaction was terminated with $0.15 \mathrm{ml} 80 \%$ trichloroacetic acid. Assays were always run in duplicate.

Protein in the supernatant used for enzyme assay was estimated by the method of Lowry, Rosebrough, Farr \& Randall (I95I). Specific activities were calculated as nmol glyoxylate/ $\mathrm{mg}$ protein/min.

Kinetics of ATP synthesis. Algae were grown photoautotrophically in medium T8. Portions of 50 or $100 \mathrm{ml}$ were removed aseptically. The algae were collected by centrifugation, washed with cold, sterile medium, and resuspended in $\mathrm{I} 25 \mathrm{ml}$ sterile medium G containing $0.2 \%$ sodium acetate dihydrate. The suspension was stirred in total darkness at $2 \mathrm{I}{ }^{\circ} \mathrm{C}$. Samples $(0.2 \mathrm{ml})$, taken at intervals, were plunged immediately into $5 \mathrm{ml}$ boiling tris buffer $(\mathrm{pH} 7.8)$, and then cooled and frozen. ATP was assayed by the fire-fly luciferase assay of Holm-Hansen \& Booth (I966).

Uptake of labelled acetate. [U- $\left.{ }^{3} \mathrm{H}\right]$ acetate was used to study the relative rates of acetate incorporation under several conditions. Algae of both the wild-type and the mutant were grown autotrophically at $2 \mathrm{I}{ }^{\circ} \mathrm{C}$. Samples $(100 \mathrm{ml})$ of the culture were removed aseptically. Organisms collected by centrifugation were resuspended in $250 \mathrm{ml}$ sterile medium containing $0.2 \%$ sodium acetate. Algal suspensions were kept in darkness, or in the light, with or without DCMU. Algae of the wild-type, grown in darkness on acetate, were similarly treated and kept in the dark. After $48 \mathrm{~h}$ (by which time preliminary experiments had shown that isocitrate lyase would be fully induced), the algae were removed by centrifugation, washed with sterile medium $\mathrm{G}$, and resuspended in $125 \mathrm{ml}$ of this medium. [U- ${ }^{3} \mathrm{H}$ ]sodium acetate ( $50 \mu \mathrm{Ci} / 0 \cdot 25 \mu$ moles) was added to each of the 7 flasks. Samples $(5 \mathrm{ml})$ were removed at intervals, $2.5 \mathrm{ml}$ added rapidly to $0.5 \mathrm{ml}$ of buffered formalin, and of this $\mathrm{I} \mathrm{ml}$ filtered through a $0.45 \mu \mathrm{m}$ Millipore membrane filter. The algae were thoroughly washed with $30 \mathrm{ml}$ cold medium G, the filter air-dried, the rim carefully cut off and discarded, and the rest of the filter cleared in scintillation fluid containing $280 \mathrm{ml}$ Bio-Solv (Beckmann Instruments, Inc.); $3.6 \mathrm{~g}$ 2,5-diphenyloxazole (PPO); 0.36 g I,4-bis-2-(4-methyl-5-phenyloxazolyl)-benzene (POPOP) and $720 \mathrm{ml}$ toluene. A further $\mathrm{r} \mathrm{ml}$ of each algal suspension was filtered through glass-fibre paper (Whatman $\mathrm{GF} / \mathrm{C}$ ) and washed with a small volume of medium $\mathrm{G}$; the filters were stored in darkness at $-20^{\circ} \mathrm{C}$. Chlorophyll $a$ determinations were carried out by grinding the filters in a tissue homogenizer with $90 \%$ acetone, and estimating the chlorophyll $a$ fluorometrically by the method of Holm-Hansen, Lorenzen, Holmes \& Strickland (1965). 


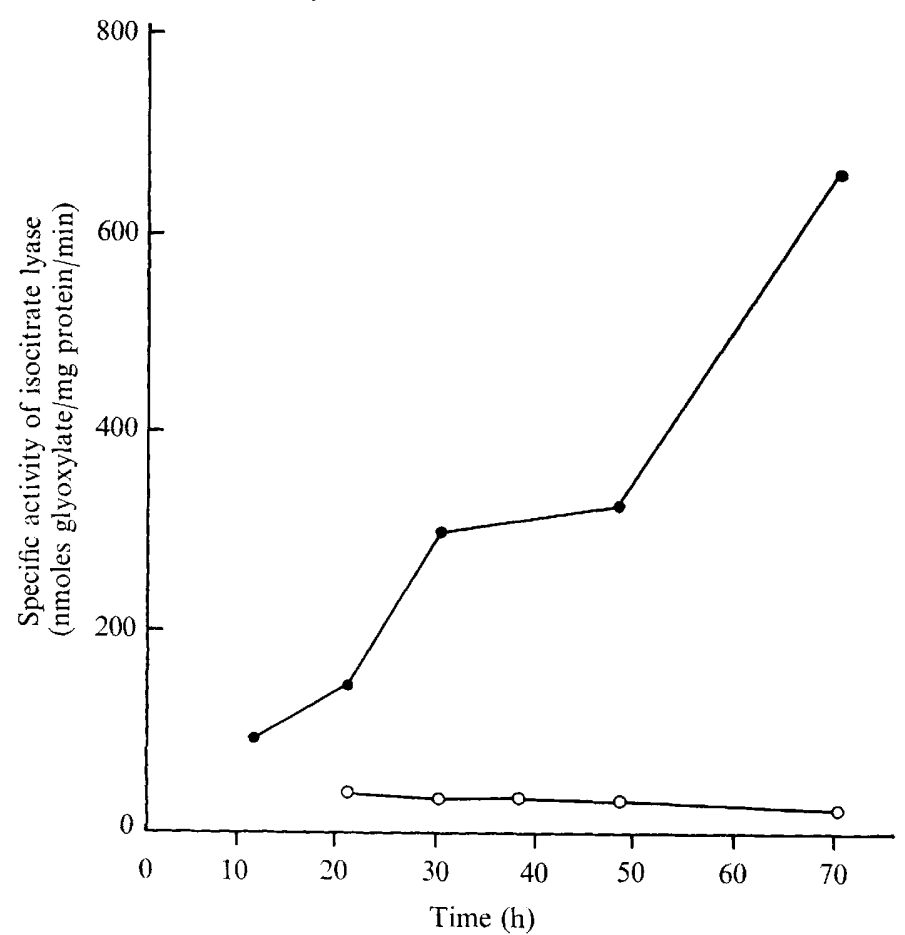

Fig. I. Synthesis in the dark of isocitrate lyase by wild-type and mutant Chlamydomonas dysosmos in the presence of acetate $(0.2 \%): 0$, wild-type cells; $O$, mutant cells.

\section{Growth experiments}

RESULTS

The wild-type strain grew heterotrophically in the dark on $0.1 \%$ acetate agar but the mutant did not, even after 6 weeks, though all plates in the light showed good growth. Evidently the strains had not basically altered their metabolic capacities through successive subcultures during the $\mathrm{I} 6$ years since the original study. In liquid medium $\mathrm{G}$, the growth rates of both strains in the light were unaffected by acetate. In the mineral medium, DCMU at $10^{-5} \mathrm{M}$ totally suppressed photosynthetic growth of both strains; this inhibition could be relieved by acetate in only the wild-type.

\section{Induction of isocitrate lyase}

In darkness. Fig. I illustrates the kinetics of enzyme synthesis when algae growing autotrophically in the mineral medium were transferred to darkness and supplied with acetate. The wild-type synthesized enzyme of high specific activity, though at a relatively slow rate. By comparison, the enzyme assay of the mutant did not increase above the background level; we assume that, if we were to correct for $\alpha$-ketoglutarate in the crude extract, this apparent activity would indeed have been zero. In both cases, during the course of the experiment there was no growth, as indicated by essentially constant chlorophyll levels.

In the light. There was no enzyme synthesis by either the wild-type or the mutant in the light, and values after $54 \mathrm{~h}$ did not rise above the background levels observed at the beginning of the experiment. By contrast, with DCMU to suppress photosynthesis in the light, enzyme was synthesized by the wild-type as in the dark, though there was no net synthesis by the mutant. Fig. 2 shows the kinetics of synthesis by the wild-type, with and without DCMU, and by the mutant with DCMU. 


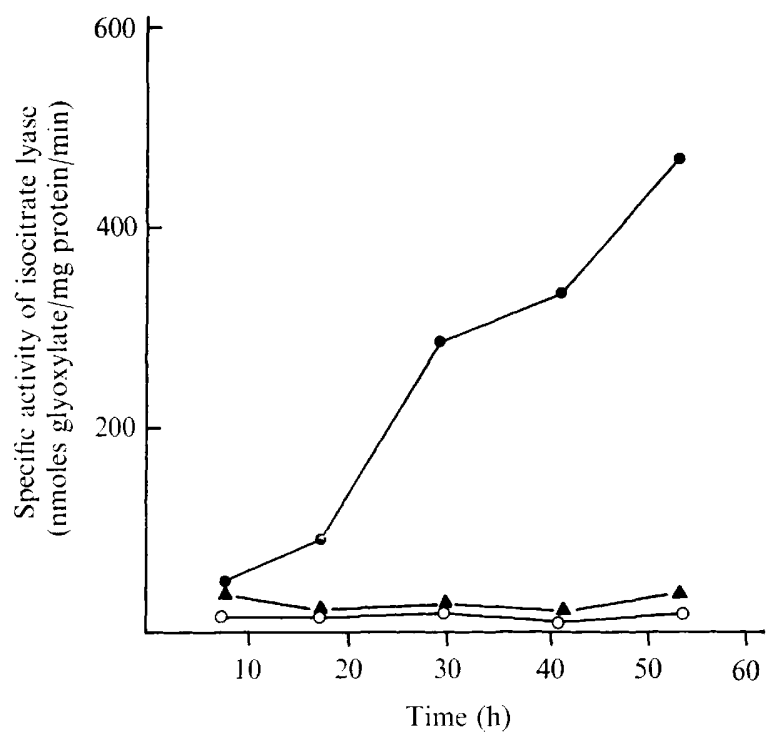

Fig. 2. Synthesis in the light of isocitrate lyase by wild-type and mutant Chlamydomonas dysosmos in presence of acetate $(0.2 \%)$ and $\operatorname{DCMU}\left(\mathrm{IO}^{-5} \mathrm{M}\right): \boldsymbol{\Delta}$, wild-type in the light; $\boldsymbol{O}$, wild-type in the light in presence of DCMU; $O$, mutant in the light in presence of DCMU.

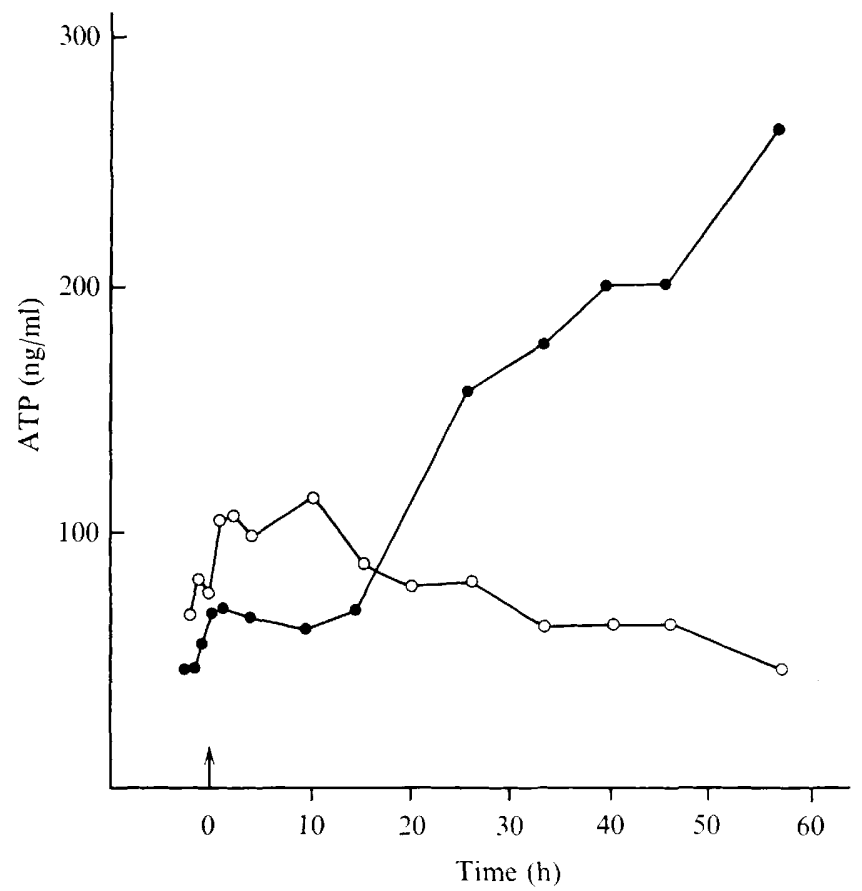

Fig. 3. Synthesis of ATP by oxidation of acetate in the dark by Chlamydomonas dysosmos: $\mathbf{0}$, wildtype; $O$, mutant. Acetate added, and algae transferred to darkness, at time indicated by arrow. 


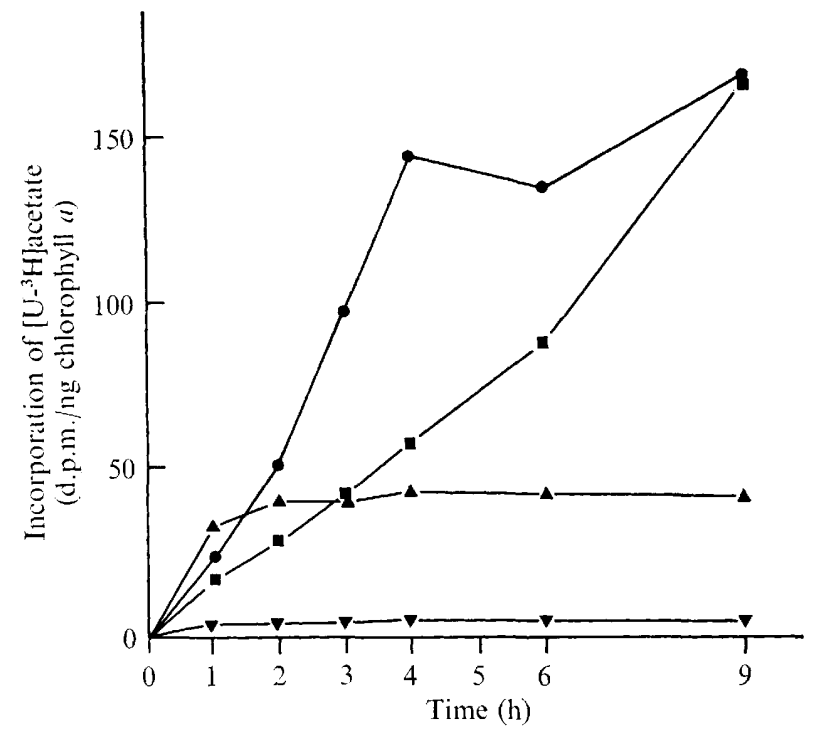

Fig. 4. Specific incorporation of $\left[\mathrm{U}-{ }^{3} \mathrm{H}\right]$ acetate into wild-type Chlamydomonas dysosmos which had been adapted to acetate for $48 \mathrm{~h}$ in darkness: $\boldsymbol{\nabla}$, in the light; $\boldsymbol{\Delta}$, in the light in presence of DCMU; , in the dark; $\square$ in the dark by algae which had been growing on acetate in darkness.

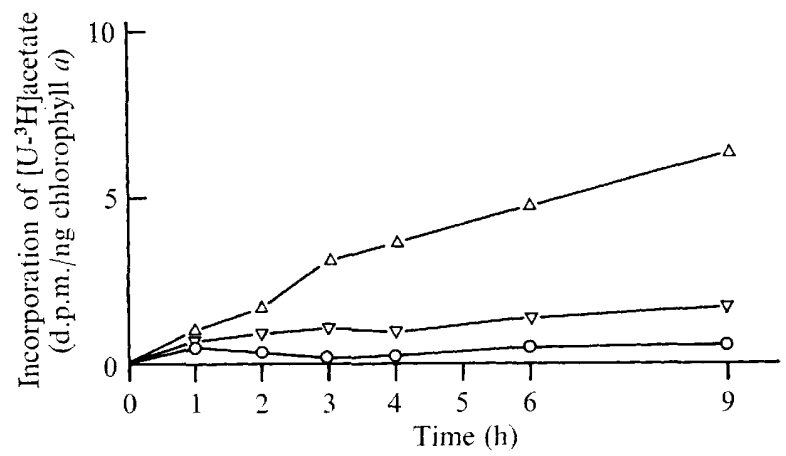

Fig. 5. Specific incorporation of [U- $\left.{ }^{3} \mathrm{H}\right]$ acetate by mutant Chlamydomonas dysosmos (strain D2075):

$\nabla$, in the light; $O$, in darkness: $\triangle$, in the light in presence of DCMU.

\section{ATP synthesis in darkness}

ATP levels were measured in the light for $2 \mathrm{~h}$ and after addition of acetate and transfer to darkness for $5^{8} \mathrm{~h}$; this period was long enough for full expression of heterotrophic potential. Results of one of two essentially identical experiments are shown in Fig. 3. Over the first ro $h$ or so, after addition of acetate, there was a small, though significant, rise in the level of ATP for both wild-type and mutant algae. Thereafter the ATP content in the mutant fell slowly and steadily, whereas there was a rapid and continued rise in that synthesized by the wild-type.

\section{Incorporation of $\left[U^{-3} H\right]$ acetate}

These experiments were carried out with algae which had previously been incubated with acetate for $48 \mathrm{~h}$, so their ability to take up and incorporate acetate was more or less fully expressed. The extent and kinetics of incorporation into the wild-type and mutant algae 
are shown in Fig. 4 and 5. In wild-type algae kept in darkness (Fig. 4) there was a relatively rapid uptake which resulted after $9 \mathrm{~h}$ in specific activities of about $\mathrm{I} 60 \mathrm{~d}$.p.m./ng chlorophyll a. This is about four times that attained by algae kept in the light with DCMU, and 40 times that taken up in the light without DCMU. In the mutant strain (Fig. 5) there was effectively no uptake, either in the light or in darkness, though there was a slow and small uptake by algae incubated in the light in the presence of DCMU. In these the maximum specific activity reached after $9 \mathrm{~h}$ of incubation was about $6 \mathrm{~d}$.p.m./ng chlorophyll $a$. Both the wild-type and the mutant algae incorporated little acetate in the light, and significant incorporation occurred in only the wild-type, either in the dark or in the presence of DCMU in the light.

\section{DISCUSSION}

Little is known of metabolic activity of Chlamydomonas dysosmos. In heterotrophically growing $C$. dysosmos, acetate is metabolized by two pathways: the tricarboxylic acid cycle, in which total dissimilation of acetate leads to sustained synthesis of ATP, and the glyoxylate cycle, which furnishes carbon skeletons for growth. Operation of the latter cycle requires the synthesis of several adaptive enzymes. One of these, isocitrate lyase, is formed only under conditions of active acetate assimilation when photosynthesis is blocked, either in darkness or by addition of $N$-(3,4-dichlorophenyl)- $N^{\prime}, N^{\prime}$-dimethyl urea (DCMU). At 2 I ${ }^{\circ} \mathrm{C}$ isocitrate lyase formation in the dark begins within $10 \mathrm{~h}$, and after $70 \mathrm{~h}$ reaches a specific activity of around $700 \mathrm{nmol}$ glyoxylate $/ \mathrm{mg}$ protein/min. Algae adapted to acetate for $48 \mathrm{~h}$ actively assimilate acetate.

In wild-type Chlamydomonas dysosmos the synthesis of ATP from acetate in the dark, and the induction of isocitrate lyase and incorporation of labelled acetate, both in darkness and with DCMU in the light, are consistent with the facultatively heterotrophic capacity of the alga and the normal functioning of the tricarboxylate and glyoxylate cycles for energy production and biosynthesis. Our results in general confirm those of Haigh \& Beevers ( I 964), except for our finding that synthesis of isocitrate lyase is repressed under photoautotrophic conditions even in the presence of acetate. However, we carried out all our experiments in an atmosphere of air, without special precautions to exclude $\mathrm{CO}_{2}$; and it is known that the cellular activity of isocitrate lyase in Chlorella vulgaris grown in the absence of $\mathrm{CO}_{2}$ is ten times as high as in cells grown in its presence (Syrett et al. 1963).

Failure of the mutant to synthesize isocitrate lyase either in darkness or in the presence of DCMU in the light, and its consequent inability to achieve balanced synthesis of ATP and incorporation of acetate in the dark, provide a simple explanation for its obligate photoautotrophy. This contrasts with the situation in algae like Pyrobotrys stellata, which apparently cannot grow on acetate in darkness in spite of the proven presence of both isocitrate lyase and malate synthetase in cells of this species (Goulding \& Merrett, 1967). It seems that it is not possible to adduce a single common explanation for obligate autotrophy.

It is a pleasure to thank Dr T. Berman, Kinneret Limnological Laboratory, Israel, for advice on the design of experiments on the uptake of labelled acetate. This work was supported in part by the National Science Foundation Grant GV 27r Io, and the United States Atomic Energy Commission Contract no. AT(I I-I)GEN Io, P.A. 20. 


\section{REFERENCES}

Goulding, K. H. \& Merrett, M. J. (1967). The photo-assimilation of acetate by Pyrobotrys (Chlamydobotrys) stellata. Journal of General Microbiology 48, 127-136.

HAIGH, W. G. \& BeEVERS, H. (1964). The occurrence and assay of isocitrate lyase in algae. Archives of Biochemistry and Biophysics 107, 147-I5I.

HoAre, D. S., HoAre, S. L. \& Moore, R. B. (1967). The photo-assimilation of organic compounds by autotrophic blue-green algae. Journal of General Microbiology 49, 351-370.

Holm-Hansen, O. \& Booth, C. R. (I966). The measurement of adenosine triphosphate in the ocean and its ecological significance. Limnology and Oceanography $11,510-519$.

Holm-Hansen, O., Lorenzen, C., Holmes, R. \& Strickland, J. (1965). Fluorometric determination of chlorophyll. Journal du Conseil. Conseil permanent international pour l'exploration de la mer 30, 3-I5.

Hughes, E. O., GoRham, P. R. \& ZeHNDeR, A. (1958). Toxicity of a unialgal culture of Microcystis aeruginosa. Canadian Journal of Microbiology 4, 225-236.

JACOBSON, L. (I95I). Maintenance of iron supply in nutrient solutions by a single addition of ferric potassium ethylenediamine tetraacetate. Plant Physiology 26, 4 I I-4I 3.

KeLLY, D. P. (1967). The incorporation of acetate by the chemoautotroph Thiobacillus neapolitanus strain c. Archiv für Mikrobiologie 58, 99-1 I6.

KorNBERG, H. L. (1966). The role and control of the glyoxylate cycle in Escherichia coli. Biochemical Journal 99, I-II.

LeWIN, J. \& Lewin, R. A. (1967). Culture and nutrition of some apochlorotic diatoms of the genus Nitzschia. Journal of General Microbiology 46, 36I-367.

LEWIN, R. A. (195I). Isolation of sexual strains of Chlamydomonas. Journal of General Microbiology 5, 926-929.

LEwIN, R. A. (1954). The utilization of acetate by wild-type and mutant Chlamydomonas dysosmos. Journal of General Microbiology II, 459-47I.

Lowry, O. H., Rosebrough, N. J., Farr, A. L. \& Randall, R. J. (1951). Protein measurement with the Folin phenol reagent. Journal of Biological Chemistry 193, 265-275.

MCFADDEN, B. A. (1969). Isocitrate lyase. In Methods in Enzymology, vol. 13, pp. I63-170. Edited by J. M. Lowenstein. New York: Academic Press.

Peeters, T. L., Liu, M. S. \& Aleem, M. I. H. (1970). The tricarboxylic acid cycle in Thiobacillus denitrificans and Thiobacillus A2. Journal of General Microbiology 64, 29-35.

Smith, A. J., London, J. \& Stanier, R. Y. (1967). Biochemical basis of obligate autotrophy in blue-green algae and thiobacilli. Journal of Bacteriology 94, 972-983.

SyreTt, P. (1966). The kinetics of isocitrate lyase formation in Chlorella: evidence for the promotion of enzyme synthesis by photophosphorylation. Journal of Experimental Botany 17, 64I-654.

Syrett, P. J., Merrett, M. J. \& Bocks, S. M. (1963). Enzymes of the glyoxylate cycle in Chlorella vulgaris. Journal of Experimental Botany 14, 249-264. 